\title{
Why is the output of medical research from India low?
}

\author{
Sunil K Pandya
}

Inaugurating a recent meeting on the methodology of research in clinical oncology at the Tata Memorial Hospital, Dr Praful B Desai, director of the hospital, posed this question about Indian medical research. A variant has been troubling scientists in general in this country for some time.

Dr Desai pointed out that there is a progressive increase in the number of doctors in India. There is also an increase in the number of medical colleges, institutes catering to specialties, and institutes set up to carry out basic research. The government of India, through the Indian Council of Medical Research, Department of Science and Technology, Department of Biotechnology, and other such outlets, is disbursing much money for research. We have a large amount and wide variety of "clinical and pathological material" (to use the impersonal phrase denoting patients and their illnesses). And yet, so little of what is published is worth the paper it is printed on. The number of medical journals in India is rising rapidly, but their contents, regularity, and quality of production leave much to be desired. Many journals have a rejection rate of less than $20 \%$ (to be contrasted with the rejection rate of over $80 \%$ at the British Medical fournal).

Why is this so? Those at the helm proclaim that lack of money is not the reason. Younger medical scientists disagree. Despite the many and varied schemes put forward by the funding agencies referred to above the fact remains that funds are obtained with great difficulty by the unknown scientist. The applicant is smothered by red tape. It is not unusual for a granting agency bursting with photocopying machines and computers to demand 20 or more copies of applications. Each application has to be accompanied by essays crammed with statistics and references that run into 50 or more pages. The young scientist is daunted by these requirements.

Of late, some funding agencies seem to be prepared to help by providing detailed guidance and are offering guidance by an established researcher that will enable the young applicant to overcome hurdles. Even so, much time, effort, and money have to be spent merely in applying for a grant.

Having made the application, the young scientist may find that the grant has been given to "an individual with a track record." It is an unfortunate fact that mutual back patting is rampant among those constituting the expert committees of these grant giving agencies. A study of the recipients of large grants will confirm this. And yet, when the scientific output of these individuals is weighed in the international arena it proves woefully deficient, bearing no relation to financial input.

Young scientists fortunate enough to receive grants cannot heave sighs of relief and proceed with their work. They remain entangled in red tape and find that they have to fill in countless forms, submit reports at frequent intervals, and remain at the beck and call of the directors of the grant giving agencies. How are they to think, perchance dream, permit the imagination to soar, and search for a breakthrough? Indeed, most medical bureaucrats would promptly slash the research application of anyone who deems such activities of the mind necessary for research! It is not surprising that much that passes for research in India is re-search, parading over well trampled ground.

Those familiar with the Indian scene will nod their heads in agreement with a perceptive statement made by a Japanese observer. He pointed out that, although in Japan there are all braves and no chiefs, in India there are all chiefs and no braves. The spirit of cooperative endeavour is conspicuous by its absence. Projects are built around individuals. Those working on similar or identical projects rarely cooperate or avoid duplication (of equipment, effort, and output)on the contrary, everything possible is done to undermine the "opponent" (as the other researcher is viewed). It is not surprising that under these circumstances time and effort are spent in conflict and other negative activity, to the detriment of the work at hand.

Dr Desai referred to suppression of promising young researchers by their seniors. The latter, past their creative phases, cannot tolerate the idea that their juniors may surpass them. In a land where, by tradition, teachers have striven to produce students who will excel them, such pettymindedness is out of place. And yet, exist it does. It is not uncommon for chiefs of sections, departments, and even institutes to insist that their names shall figure as principal investigators on all applications for research grants and as first authors on all publications regardless of the fact that they may have neither the time nor the energy to give more than a cursory glance to what is to be done or being done.

In the handful of institutions where conditions are ideal for young researchers they face yet another frustration. The number of individuals working in sophisticated fields is severely limited. Thus a molecular biologist working on the intricacies of cell membranes may have no one else in the country on whom he can call for guidance, help, or brainstorming. It becomes necessary for him to travel far afield - to Europe or the United States - for such interaction. Often he finds it easier to settle there so that he can work among colleagues who understand the problems and can guide, advise, and encourage.

Perhaps the most important deficiency is a lack of the culture of research. Most of us, burdened with routine-and content to be thus burdened-have neither the time nor the energy to do anything more. It is the exceptional neurosurgeon who ventures into the field of neural transplants and neurobiology and the exceptional cardiac surgeon who sets up a laboratory for biomedical engineering.

I found consolation in Dr Desai's remarks after the inauguration. The times, they're a changin', he pointed out. Gradually - with almost painful slowness -individuals, groups, and institutes are making a mark on the national and international canvas. There is a distinct change in the outlook of the Departments of Science and Technology and Biotechnology. In striking contrast to what obtained a decade or two ago, many of our gifted and creative youngsters are returning to India after a stint abroad, finding the need and conditions in India attractive. The situation may not, after all, be as grim as the earlier part of this essay makes it out to be.
Sunil K Pandya, MS neurosurgeon

BrMed I 1990;301:333 